Revista Destaques Acadêmicos, Lajeado, v. 12, n. 2, 2020. ISSN 2176-3070

DOI: http://dx.doi.org/10.22410/issn.2176-3070.v12i2a2020.2549

http://www.univates.br/revistas

\title{
O SECRETÁRIO ESCOLAR DA EDUCAÇÃO PÚBLICA DO DISTRITO FEDERAL
}

\author{
Antonio Gomes da Costa Neto ${ }^{1}$
}

Resumo: O presente artigo versa sobre o secretário escolar, a partir da Lei de Diretrizes e Bases da Educação Nacional (LDB), por força de lei (12.014/2009), a qual incluiu os trabalhadores da educação não docentes como profissionais da educação escolar básica e sua relação com a profissão do Secretário (7.377/1985), a partir da análise do Secretário Escolar da Carreira Pública do Distrito Federal. A metodologia utilizada é qualitativa, exploratória por meio de análise documental e documentos fornecidos pela da Lei de Acesso a Informação (LAI). Os resultados alcançados revelam a invisibilidade e a desvalorização do Secretário Escolar, além da necessidade de inclusão do Secretariado Executivo na categoria de profissionais da educação.

Palavras-chave: Secretário Escolar; Secretariado Executivo; Profissionais da Educação

\section{INTRODUÇÃO}

O secretário escolar, apesar dos avanços nas normas educacionais brasileiras, ainda busca o seu reconhecimento dentro dos órgãos de educação escolar, cuja ausência de reconhecimento profissional, bem como as demais funções ligadas às áreas não docentes tem como característica a ausência de estudos capazes de proporcionar o empoderamento profissional.

A falta de visibilidade profissional decorre da vinculação direta com a escravidão, a qual suas atribuições têm origem em relação aos trabalhadores das áreas de "limpeza, e, com o decorrer do tempo, à merenda escolar, secretaria e mecanografia" (COSTA NETO, 2019, p. 236; COSTA NETO, 2012a; LOPES, 2003; NASCIMENTO, 2006; NASCIMENTO, 2010b; SILVA, 2003).

Notadamente, as principais alterações do perfil desses profissionais foram promovidas, inicialmente, por meio da Resolução n. 5/2005, do Conselho Nacional de Educação (CNE), quando naquele momento instituiu a $21^{\text {a }}$ Área Profissional de Apoio Escolar, processo embrionário de futuro reconhecimento na esfera laboral.

1 Doutor em Ciências Sociais e Mestre em Educação, Universidade de Brasília (UnB). 
Porém, fator relevante para essa modificação processa-se pela inclusão desses trabalhadores no grupo de profissionais da educação básica, cuja causa fundante é a iniciativa da então senadora Fátima Cleide (PT/RO) quando propôs o Projeto de Lei do Senado 507/2003, posteriormente, transformado na Lei (12.014/2009), o qual promoveu o reconhecimento desses educadores como profissionais da educação escolar.

Entretanto no Catálogo Nacional de Cursos Técnicos (Portaria n. $870 / 2008$ ) integra a área de apoio escolar ${ }^{2}$ em sua primeira edição e nas subsequentes (2012 e 2014), por sua vez em relação ao programa de formação profissional Profuncionário (Portaria Normativa 25/2007) não figurava entre as habilitações, eis que restringiam as demais em nível médio nas áreas de Gestão Escolar, Alimentação Escolar, Multimeios Didáticos, Meio Ambiente e Manutenção da Infraestrutura.

Situação posteriormente alterada com a inclusão na formação profissional em 2010, por força de decreto $(7.415 / 2010)$, de igual sorte com a inclusão das áreas de biblioteconomia e Orientação Comunitária, além da formação continuada em nível superior e pós-graduação, porém, ainda pendente de institucionalização pelos Estados e Municípios por meio dos Fóruns de Formação Profissional, os quais atuam por demanda ou iniciativa (COSTA NETO, 2016, 2019a).

No tocante à Política de Formação Nacional (Decreto 8.752/2016), de igual sorte encontra-se regulamentado nas Diretrizes Nacionais dos Funcionários da Escola (Resolução n. 05/2010), da Câmara de Educação Básica (CEB) do Conselho Nacional de Educação (CNE), mecanismos legais demonstrativos do direito à integração do Secretário Escolar nas Políticas Educacionais de formação inicial e continuada, bem como deram impulso ao direito do reconhecimento como profissão.

O presente artigo discorre sobre o papel do secretário escolar, a partir da alteração da Lei de Diretrizes e Bases da Educação Nacional (LDB), por força de lei (12.014/2009), a qual inseriu os trabalhadores da educação não docentes como profissionais da educação escolar básica, apesar da existência da regulamentação da profissão em Lei do Secretário $(7.377 / 1985)$ circunscrevendo-se a pesquisa ao Secretário Escolar da Carreira Pública do Distrito Federal.

A metodologia utilizada é qualitativa, exploratória por meio de análise documental, cujos dados foram identificados e identificados por meio da Lei de Acesso a Informação (LAI) a partir de achados identificados sobre os Profissionais da Educação Pública do Distrito Federal, com ênfase no cargo público de Secretário Escolar atuantes em Escolas Públicas e na área de Gestão

2 O Técnico em Secretariado consta de igual forma no eixo Gestão e Negócios. 
Governamental, quando observado suas atribuições conforme dispõe a legislação educacional e profissional.

Inicialmente, devemos nos ater as diferenças funcionais do Secretariado Executivo, Secretário e Secretário Escolar segundo as normas de regulamentação da profissão, ou seja, "os bacharéis se tornam, após graduados, 'secretários executivos', diferentemente dos técnicos que, após graduados, são denominados 'secretários' (CANTAROTTI, 2018, p. 24). Motivo da escolha de pesquisa em relação ao Secretário Escolar.

Porém, para compreender se as competências profissionais do Secretário Escolar encontram-se inseridas na regulamentação da profissão de Secretário, de modo a corroborar nossa análise buscamos identificar junto ao órgão estatal de inscrição do trabalhador, para fins de convergência entre o Secretário e o Secretário escolar como se procede ao registro para fins de exercício como profissão.

Foucault $(2007,2010)$ assevera que toda institucionalização é realizada perante um "aparelho pedagógico" para produzir uma verdade daquele que detém o poder, ligado pelas regras do direito, ou seja, por normais legais no que denominou do triângulo poder, direito e verdade. Nesse ponto devemos dirimir a dúvida sobre o secretário escolar para fins profissionais decorrente do reconhecimento pedagógico.

Consultado o órgão de regulação do Estado em relação profissional do Secretário Escolar, ainda na vigência da legislação de requisito de registro, obrigatoriedade revogada em 2019 (Medida Provisória 905/2019). Foinos informado que o "curso de Técnico em Secretaria Escolar habilita o seu concluinte a obtenção do registro profissional de Técnico em Secretariado" (ECONOMIA, LAI, 2019). Portanto, como profissão equipara-se ao Secretário.

Posto isso o Secretário Escolar pode ser compreendido de duas formas: portadores de diploma de nível superior e aqueles com curso técnico profissionalizante. Essa diferença deve ser considerada para fins de formação inicial e continuada de profissionais da educação, uma vez que a legislação educacional estabelece como necessária a formação em curso técnico ou superior (LDB) na estrutura da educação (COSTA NETO, 2013).

Diferenciação para fins de nível da estrutura da educação a qual deve ser pensada no tocante as atividades de regulação do Estado, ou seja, aquelas atribuições relacionadas ao poder de polícia administrativa inseridas nos atos de fiscalização e controle, logo, o Secretário Escolar tem atuação profissional nas atividades de Estado, exclusivas de servidores públicos, além de outras funções inerentes as instituições de ensino públicas e privadas.

Em relação às atividades exclusivas do Estado integram as funções de fiscalização, regulação, fomento, avaliação de políticas e serviços educacionais perante o órgão de educação, cujo Secretário (Executivo e Escolar) é de extrema relevância, especialmente, nos atos de entrada (credenciamento e autorização) e 
de permanência (recredenciamento e transformação de organização acadêmica; reconhecimento e renovação de reconhecimento) das instituições de ensino da educação básica e superior.

De acordo Almeida e ali (2018) o Secretário Escolar deve ter conhecimento específicos sobre a área, além de interação com toda a unidade acadêmica, é responsável pela organização da escrituração escolar, contribuem com a produção de insumos para as pesquisas educacionais, bem como para o exercício profissional devem ter o reconhecimento profissional por lei (ABUD, 2012).

Depreende-se das atividades desenvolvidas em unidades educacionais, há envolvimento com a comunidade escolar, compõe a equipe gestora, sua responsabilidade é ampla em todos os ambientes institucionais, cujas atribuições podem ser observadas nas relações entre a escola, a comunidade, a gestão interna e externa, bem como para com a fiscalização junto aos órgãos educacionais (GEANINI, 2011).

Por sua vez às práticas inerentes as atividades administrativas do Estado, pouca atenção tem sido reservada a atuação do Secretario, especialmente, pelo fato de que o ensino é comumente tratado como educação, situações divergentes, eis que na organização administrativa do Estado as funções típicas do Estado não são aqueles inerentes à função social (ensino), a qual não pode ser atribuída à iniciativa privada.

Dessa forma o Secretariado Executivo deve ser compreendido como inerente às atividades de Estado, encontra-se inserido na esfera da regulamentação da Profissão do Secretário e depende de concurso público, deve ter nível superior para o Secretário Executivo e nível técnico para Secretário Escolar, conforme as atribuições desempenhadas, ou seja, o Secretário é essencial no âmbito profissional e educacional (HEPP, MARTINS, 2009; KONRAD, BORGHETTI, 2010).

\section{O Secretário Escolar no Distrito Federal}

O Secretário Escolar da esfera pública do Distrito Federal tem sua origem perante Fundação Educacional Brasília (FEB), posteriormente, Fundação Educacional do Distrito Federal (FEDF) em 1960, organizado profissionalmente na esfera pública por meio da Carreira Assistência a Educação do Distrito Federal (1989), distribuídos segundo a área governamental.

Esse profissional integra a área da Educação Pública do Distrito Federal dentro da Carreira Assistência a Educação do Distrito Federal (Lei 5.106/2013), encontra-se definido no cargo de Técnico de Gestão Educacional, Especialidade Secretário Escolar, cuja força de trabalho é composta de 687 trabalhadores, em relação ao total de servidores ativos de 2.748 profissionais do mesmo cargo em diversas especialidades (EDUCAÇÃO, LAI, 2019). 
Em período pretérito antes da vigência da Lei 5.106/2013, os cargos de Técnico de Gestão Educacional, Especialidade Secretário Escolar poder-se-iam ingressar em nível médio e superior, porém, pela ausência de regulamentação o Tribunal de Contas do Distrito Federal (TCDF) em decisão do ano de 2012 determinou a atualização dos perfis profissionais, todavia, o órgão de educação quedou-se inerte sobre a profissão em nível superior e definiu-a em nível técnico a partir de 2013 (COSTA NETO, 2020).

Por essa razão disciplinou o ingresso no cargo público tão somente em nível médio, além da necessidade de aprovação em concurso público, de prova e de títulos, eis que como profissional da educação segue as regras estabelecidas pela Constituição Federal, possui como requisito para o exercício profissional de curso de nível técnico em nível médio, cujas atribuições funcionais estão definidas em diversos normativos do sistema de ensino do Distrito Federal $(28 / 2016)$.

Segundo o Regimento Interno da Secretaria de Educação do Distrito Federal (2019), a Secretaria Escolar é dirigida por um Chefe de Secretaria devidamente habilitado, ou seja, não se trata de função exclusiva do profissional Secretário Escolar, mas uma função gratificada pelo exercício das atribuições inerentes ao cotidiano da secretaria escolar, o qual integra a equipe gestora da escola.

Em relação ao Manual da Secretaria Escolar (SEDF, 2018) por sua vez estabelece o Secretário Escolar, inicialmente, equipara-se ao Chefe de Secretaria, com as diversas atribuições inerentes a estruturação escolar, o qual poder ser atribuída ao profissional de outra especialidade administrativa por meio de autorização provisória, não se trata de atividade exclusiva.

\section{Análise e Discussão}

Precipuamente, devemos tecer algumas considerações acerca do Secretário Escolar, Secretário e Secretário Executivo, e como estão disciplinadas suas atribuições dentro da educação pública, cuja temporalidade pode-nos auxiliar em relação às situações decorrentes da profissão, eis que as questões atinentes ao profissional altera de forma substancial o desenvolvimento da profissão, e da carreira no Distrito Federal.

Como se observa pela regulamentação da profissão de secretário é do ano de 1985, porém, antes da vigência da norma já existia o secretário escolar na educação pública e na área privada, nesse caso, a ausência de medidas legais não haveria óbice no sentido do reconhecimento profissional, eis que somente a partir de 2002 o Conselho Nacional de Educação promoveu a normatização do Curso de Secretariado Executivo (Parecer 146/2002).

Como se verifica a carreira assistência é regulamentada em 1989 (Lei 83) oriunda dos empregos públicos criados em 1960, nesse caso, apesar das funções institucionais do órgão de educação, as atribuições seriam inerentes 
ao apoio de funcionamento das áreas administrativas, além de contribuir com os trabalhadores responsáveis pela função social (magistério). Logo, os empregados públicos (assistência e docentes) não integravam as funções típicas de Estado.

Porém, em relação às atividades educacionais, especialmente, nas atribuições e exercício profissional, por norma interna do Distrito Federal exigia-se a profissionalização em Técnico em Secretaria Escolar (1985), contudo com exceções para exercício daqueles com curso de Aperfeiçoamento (2003), posteriormente, com a exigência de ingresso em curso técnico (2010).

Essa situação na educação pública do Distrito Federal quando observada a Lei 83/1989, em razão do vínculo na condição de empregados públicos, aqueles que cumprissem os requisitos para a "ascensão" funcional poderiam exercer os cargos em nível superior, todavia, essas novas atribuições seriam em novos empregos, cujo Secretariado inexistia na carreira ou qualquer alusão a esse profissional.

Dessa forma como estavam inseridos em cursos de nível médio, e com o advento da regulamentação da profissão em 1985, haver-se-iam de ter sua contratação para o desempenho da Secretaria Escolar de unidades de ensino em nível médio com curso técnico profissionalizante, além do nível superior a partir de 2002, em atribuições de Secretariado conforme definido pela resolução do Conselho Nacional de Educação, fato que não ocorreu.

Todavia, aqueles selecionados para atividades junto às funções de supervisão, fiscalização e orientações de normas educacionais deveriam ser feitas em nível superior - secretariado executivo -, o que necessitaria de adequação dos planos de carreira, situação que somente ocorreria em 2012, por força de determinação do Tribunal de Contas, contudo, o órgão de educação não realizou dentro da vigência da legislação, houve alteração e o retrocesso do nível de ingresso para nível técnico profissional a partir do ano de 2013.

Esse fato é de extrema importância, uma vez que a legislação da carreira assistência à educação foi modificada em diversas oportunidades, quando o Tribunal de Contas do Distrito Federal (TC 14822/2012 - Decisão 89/20123) determinou a elaboração de novo perfil profissiográfico da Carreira Assistência vigia o plano de Carreira (Lei n. 4.458/2009 e Lei 3.319/2004), ou seja, nesse período o Secretário Escolar tinha como nível ingresso de escolaridade tanto

3 O Tribunal, por unanimidade, de acordo com o voto do Relator, decidiu: I - tomar conhecimento do resultado da inspeção realizada perante a Secretaria de Educação do Distrito Federal, em atenção à Decisão n ${ }^{\circ} 47 / 12$, item II, bem como dos documentos de fls. 25 a 48; II - indagar da Secretaria de Educação do Distrito Federal, para cumprimento em 60 (sessenta) dias, as medidas que estão sendo adotadas para: a) editar ato administrativo visando estabelecer as atribuições das especialidades que compõem os cargos públicos da Carreira Assistência à Educação do Distrito Federal (art. $3^{\circ}, \S 2^{\circ}$, da Lei DF $n^{\circ} 4.458 / 09$ ); 
em nível médio e superior. Portanto, o Secretariado Executivo deveria ter sido implementado.

Vale ressaltar que na vigência da Lei 3.319/2004 houve uma Portaria (82/2012), que tinha como foco um Grupo de Trabalho (GT) com a "finalidade de definir as funções e atribuições das especialidades que integravam os cargos da Carreira Assistência à Educação, tendo em vista sua reestruturação, de acordo com a Lei $\mathrm{n}^{\circ} 4.458$, de 23 de dezembro de 2008", cujo resultado não levou adiante as normas vigentes.

Acentua-se que o catálogo nacional de cursos técnicos (2016) ao dispor sobre o Secretário Escolar, cita as possibilidades de formação em nível superior, faz expressa alusão ao curso de secretariado executivo, demonstrando a convergência da formação continuada desses profissionais, além da necessária inserção do Secretario Executivo nas carreiras públicas educacionais nas atividades de Estado, percebe-se a falta de reconhecimento e conhecimento da área de pessoal da educação.

Porém, quando da análise pelo órgão de educação sobre esses aspectos verifica-se que inexistiu essa preocupação, esse fato tem relação direta com o que Monlevade (2009) assevera pela ausência de estudos e pesquisadores interessados pelo trabalhador não docente, além de que o trabalho desenvolvido por esses profissionais tem relação direta com atribuições estatais, o que poderia promover seu empoderamento profissional.

Denota-se o prejuízo ao Estado e ao cargo público, eis que caberia o reconhecimento de um novo perfil profissional com a edição de norma pela alteração para Secretário Executivo em nível Superior, Secretário Escolar em nível Superior, e Secretário Escolar em nível médio, eis que a legislação do período era no sentido dessa regularização, demonstrando a saciedade o não reconhecimento do profissional da educação não docente (COSTA NETO, 2020, 2019, 2016; MONLEVADE, 2009).

Essa razão pode ser observada desde a criação da pasta da educação, quando houve o aproveitamento dos profissionais docentes e não docentes, os profissionais foram distribuídos de forma conjunta, com isso houve o desvio de função em favor do magistério, inclusive com a criação do "professor administrativo" (COSTA NETO, 2019), ou seja, a invisibilidade profissional foi mantida e perpetuada.

Outro aspecto é observado quando o Conselho de Educação do Distrito Federal (CEDF), o qual em resolução promoveu a exclusão do secretário escolar do rol de profissionais da educação, por via transversa propõe a extinção do cargo público e a sua desvalorização, cuja aprovação ocorreu por unanimidade e com a colaboração dos diversos integrantes de todos os segmentos do Estado, da Sociedade e dos representantes dos profissionais da educação (CONSELHO DE EDUCAÇÃO, 2018). 
Demasiadamente estranho, uma vez que a composição do órgão de educação tem entre os seus integrantes o representante da carreira assistência à educação, a qual o secretário escolar está vinculado, além de integrantes do magistério, pesquisadores da educação, ou seja, a conclusão advinda é de que por não pertencer ao grupo de profissionais da educação seria incoerente sua participação, eis que o representante de classe do Secretário Escolar não se manifestou em sentido contrário.

Nesse sentido pela leitura das atas das reuniões realizadas pelo órgão de educação para compreender essa questão, deparamos com a ausência do representante dos Secretários Escolares no dia da votação do referido artigo, porém, nas discussões posteriores não houve intervenção contrária à exclusão, e não há manifestação por parte desse segmento sobre a possibilidade de alteração dessa situação.

Entretanto, segundo o INEP (2003) no exercício de 1991, existiam no Distrito Federal 474 estabelecimentos de ensino público com 346.549 estudantes, e 682 Secretários Escolares, enquanto em 2000 somente 382 profissionais, quando observado o exercício de 2020, das 683 instituições de ensino e dos 456.109 estudantes são 687 Secretários (EDUCAÇÃO, LAI, 2019), ou seja, decorridos 29 (vinte e nove) anos o total de profissionais se assemelha aqueles dos anos noventa, apesar do aumento das instituições e dos estudantes (EDUCAÇÃO, LAI, 2019).

Considerando que cada instituição de ensino deve funcionar para atendimento ao público de forma intermitente durante os períodos diurnos, sem considerar aquelas com funcionamento em horários noturnos, ou seja, a quantidade de profissionais para atuar nas instituições de ensino deveria ser dobrada, obrigatoriamente, deveria ser ampliada com extrema urgência, considerando o risco de nova diminuição no período com ocorreu em 2000 com apenas 382 profissionais.

Para compreender a situação do Secretário Escolar devemos observar os critérios de lotação desses profissionais nas unidades de ensino, cuja norma em vigor (Portaria n. 369/2018) disciplina a modulação de diversos cargos, entre esses o Secretário Escolar, quando observado de forma individual, em relação aos aspectos de convergência dos cargos públicos, e da função comissionada nas atividades da Secretaria Escolar (art. $9^{\circ}$ ):

$\S 1^{\circ}$ As UEs/ UEEs/ ENEs a partir de 500 (quinhentos) estudantes contarão com 01 (um) servidor para as atividades administrativas, ocupante do cargo de Técnico de Gestão Educacional Apoio Administrativo ou Secretaria Escolar, além do Chefe de Secretaria, tendo prioridade o Técnico de Gestão Educacional Secretario Escolar. 
Depreende-se da leitura da portaria tem por objetivo é o de manter tão somente um Secretário Escolar em unidades de ensino, ou seja, as escolas da rede pública de ensino devem funcionar apenas com um profissional, entretanto, são servidores designados para o desempenho das atividades junto à secretaria Escolar, em conjunto com outros ocupantes da função de Chefe de Secretaria, quiçá suas atribuições nas áreas de fiscalização e controle governamental.

E da leitura da norma verificamos que o órgão de educação equipara o cargo de Apoio Administrativo ao Secretário Escolar, porém, conforme se depreende dos perfis profissiográficos são atividades distintas, demonstrando não haver consenso na administração do que cada cargo público desempenha, além do número total dos estudantes matriculados na rede pública são superiores ao necessário para atuar de forma adequada, conforme disciplinado na portaria de modulação profissional:

$\S 2^{\circ}$ Acrescentar-se-á mais 01 (um) servidor Técnico de Gestão Educacional Apoio Administrativo ou Secretaria Escolar para cada grupo de 500 (quinhentos) estudantes, tendo prioridade o Técnico de Gestão Educacional Secretario Escolar.

$\S 3^{\circ}$ Excetuam-se do $\S 2^{\circ}$, os Centros de Ensino Especial, onde haverá 01 (um) Técnico de Gestão Educacional Apoio Administrativo ou Secretaria Escolar a cada 250 (duzentos e cinquenta) estudantes, tendo prioridade o Técnico de Gestão Educacional Apoio Administrativo, até o limite de 02 (dois) servidores.

$\S 4^{\circ}$ A distribuição dos horários e/ou dos turnos de trabalho do servidor serão definidos respeitando o tempo de serviço na UE/ UEE/ ENE e a necessidade da Administração.

Compulsando o perfil profissional editado em 2016 ao atribuir ao secretario escolar com atuação na área escolar diversa atividades, inclusive aquelas inerentes a "vida funcional dos professores e dos técnicosadministrativos" (Portaria 28/2016), ou seja, amplia as atribuições para além daquelas relativas ao profissional, denota-se o desvio de função, porém, não é de se estranhar em um órgão que possui "professores administrativos" (COSTA NETO, 2019).

Ou seja, a desvalorização profissional, levou ao não reconhecimento sem o devido direito do Secretário Escolar em nível superior, cuja regularização deveria ter ocorrido como Secretário Executivo nos termos da legislação, o que contribuiria para o bom desempenho dos sistemas de ensino, tanto na função social (ensino) e nas atividades de Estado, além de representar a melhoria dos processos gerenciais da administração pública.

\section{Considerações}

Nesse trabalho buscamos identificar o papel do Secretário Escolar da área Pública do Distrito Federal, especialmente, na consolidação como 
profissional da educação escolar, em função da existência de legislação que ampara o direito a profissão, todavia, o órgão de Educação quedou-se em proceder à regularização no período previsto pela legislação.

O Secretário Escolar da Educação Pública do Distrito Federal, no decorrer da vida profissional não lhe foi garantido à formação continuada em nível superior, o reconhecimento como profissional da educação, situação vislumbrada tão somente pelo órgão nacional de educação, sem perspectiva de alteração dentro da esfera distrital, bem com a não profissionalização por meio do Secretariado Executivo.

Por sua vez nas normas federais está previsto o direito ao reconhecimento como profissional da educação escolar, o qual tem sido paulatinamente absorvido pelas legislações e normas complementares, mais ainda não reverberou nos sistemas de ensino, demonstrando a invisibilidade, ausência de formação e reconhecimento profissional.

Outra faceta dessa desvalorização é o não estabelecimento perante o sistema de ensino do Secretariado Executivo, profissional de extrema relevância para o funcionamento dos processos gerenciais e administrativos das áreas de regulação do Estado, inclusive nas áreas de gerenciamento escolar, o que por certo contribui para melhoria da gestão pública, cujo quantitativo de secretários escolares não é superior aqueles dos anos noventa.

Denota-se a pouca atenção destinada ao Secretário Escolar e Secretariado Executivo, o que por certo influencia no cotidiano profissional, na melhoria da qualidade dos serviços em favor da sociedade, além de causar prejuízo à função social da Educação (ensino) e as demais políticas públicas, demonstrando à saciedade a importância da mudança dessa postura na estrutura da Educação em face do risco de comprometer o sistema de ensino.

\section{REFERÊNCIAS}

ABUDE, Cristiane de Ramos Abud. A função do secretário escolar na contemporaneidade: entre memórias e arquivos escolares. Revista Linguagem, Educação e Memória, v. 3, n. 3, 2012.

ALMEIDA, Veronica Lima Fonseca; DE SOUZA, Alcina Martins; OLIVEIRA, Petricelia Nunes. A Profissão e Atuação do Secretário Escolar no Ensino Público e Privado em Escolas de São Sebastião-DF. Revista de Gestão e Secretariado, [S.l.], v. 4, n. 3, p. 83-109, dez. 2013. ISSN 2178-9010. Disponível em: https:/ / revistagesec.org.br. Acesso em: 26 fev. 2020.

BRASIL. Decreto 7.415, de 09 de dezembro de 2010. Institui a Política Nacional de Formação dos Profissionais da Educação Básica. Dispõe sobre o Programa de Formação Inicial em Serviço dos Profissionais da Educação Básica dos Sistemas de Ensino Público - Profuncionário. 
BRASIL. Decreto 8.752, de 09 de maio de 2016. Dispõe sobre a Política Nacional de Formação dos Profissionais da Educação Básica.

BRASIL. Lei 12.014, de 06 de agosto de 2009. Dispõe sobre as categorias de trabalhadores que se devem considerar profissionais da educação.

BRASIL. Lei 7.377, de 30 de setembro de 1985. Dispõe sobre o exercício da Profissão de Secretário.

BRASIL. Lei 9.394, 20 de dezembro de 1996. Lei de Diretrizes e Bases da Educação Nacional.

BRASIL. Medida Provisória 905, de 11 de novembro de 2019. Dispõe sobre o Contrato de Trabalho Verde e Amarelo.

BRASIL. Ministério da Economia. Subsecretário de Políticas Públicas e Relações do Trabalho. Lei de Acesso a Informação. Processo 03006000152201969.

BRASIL. Ministério da Educação. Catalogo Nacional de Cursos Técnicos. Portaria n. 870, de 16 de julho de 2008.

BRASIL. Ministério da Educação. Conselho Nacional de Educação. Parecer 146, de 03 de abril de 2002. Diretrizes Curriculares do Curso de Secretariado Executivo.

BRASIL. Ministério da Educação. Conselho Nacional de Educação. Câmara de Educação Básica. Resolução n. 05, de 03 de agosto de 2010. Dispõe sobre as Diretrizes Nacionais para os Planos de Carreira e Remuneração dos Funcionários da Educação Básica pública.

BRASIL. Ministério da Educação. Conselho Nacional de Educação. Resolução 5, de 22 de novembro de 2005. Inclui nos quadros anexos à Resolução CNE/CEB n ${ }^{\circ} 4 / 99$, de 22/12/1999, como 21 a Área Profissional, a área de Serviços de Apoio Escolar.

BRASIL. Ministério da Educação. Portaria Normativa 25, de 2007. Institui o Programa de Formação Inicial em Serviço dos Profissionais da Educação Básica dos Sistemas de Ensino Público - PROFUNCIONÁRIO.

BRASIL. Ministério da Educação. Secretaria de Educação Profissional e Tecnológica. Catálogo Nacional de Cursos Técnicos. Ministério da Educação, 2016.

BRASIL. Senado Federal. Projeto de Lei do Senado 507, de 24 de julho de 2003. Dispõe sobre as categorias de Profissionais da Educação.

CANTAROTTI, Aline. Tradução para secretariado executivo no Brasil: uma proposta de abordagem de ensino para a graduação. Tese. Doutorado. Linguística. São José do Rio Preto, UNESP, 2018.

COSTA NETO, Antonio Gomes da. A Educação das Relações Étnico-Raciais no Brasil e Uruguai: a política institucional de combate ao racismo no sistema de avaliação da 
educação superior. Tese (Doutorado). Departamento de Estudos Latino Americanos, UnB, 2019.

A Profissão do Secretário Escolar. Revista Gestão Universitária, volume 13, ed. 5, 2020. Disponível em: http:/ / www.gestaouniversitaria.com.br/artigos/a-profissaodo-secretario-escolar. Acesso em 30 mai 2020.

Educadores na LDB: gestores, técnicos e apoio escolar. Revista Educação Pública, Volume 12, ed. 9, 2012. Disponível em: https:/ / educacaopublica.cecierj.edu. $\mathrm{br} /$ artigos /12/9/educadores-na-ldb-gestores-teacutecnicos-e-apoio-escolar. Acesso em 20 mar 2020.

A biblioteca escolar, os funcionários da escola e o Profuncionário. Revista Educação Pública, Volume 16, ed. 9, 2016. Disponível em: https:/ / educacaopublica. cecierj.edu.br/artigos/16/9/a-biblioteca-escolar-os-funcionrios-da-escola-e-oprofuncionrio. Acesso em 15 jan 2020.

. Estudo sobre a Biblioteca Escolar, os Bibliotecários e os Técnicos em Biblioteconomia da Educação Pública do Distrito Federal. Revista Eletrônica Unifacear, Volume 8, ed. 3, 2019. Disponível em: http:/ / revista.facear.edu.br/ artigo/\$/estudo-sobre-a-biblioteca-escolar-os-bibliotecarios-e-os-tecnicos-embiblioteconomia-da-educacao-publica-do-distrito-federal. Acesso em 15 mar 2020.

O "Professor Administrativo" no ensino público do Distrito Federal.

Revista Gestão Universitária, Volume 12, 2019. Disponível em: http:/ / www. gestaouniversitaria.com.br/artigos/o-professor-administrativo-no-ensino-publico-dodistrito-federal. Acesso em 15 mar 2020.

DISTRITO FEERAL. Lei 83, de 29 de dezembro de 1989. Cria a Carreira Assistência a Educação do Distrito Federal. Sistema Integrado de Normas Jurídicas do Distrito Federal.

DISTRITO FEDERAL. Lei 3.319, de 11 de fevereiro de 2004. Dispõe sobre a Carreira Assistência a Educação do Distrito Federal. Sistema Integrado de Normas Jurídicas do Distrito Federal.

DISTRITO FEDERAL. Lei 4.458, de 23 de dezembro de 2009. Dispõe sobre a Carreira Assistência a Educação do Distrito Federal. Sistema Integrado de Normas Jurídicas do Distrito Federal.

DISTRITO FEDERAL. Lei 5.106, de 2013. Dispõe sobre a Carreira Assistência a Educação. Sistema Integrado de Normas Jurídicas do Distrito Federal.

DISTRITO FEDERAL. Secretaria de Estado de Educação. Censo Escolar 2019. Disponível em: http:/ / www.se.df.gov.br/censo-escolar-2019/. Acesso em 14 março 2020 . 
DISTRITO FEDERAL. Secretaria de Estado de Educação. Conselho de Educação do Distrito Federal. Resolução 01, de 18 de dezembro de 2018. Dispõe sobre as normas para a Educação Básica do Distrito Federal.

DISTRITO FEDERAL. Secretaria de Estado de Educação. Lei de Acesso a Informação. Processo n. SEI 00080000613201912. Dispõe sobre a alteração da Resolução n. 01/2018 e 02/2019 do Conselho de Educação do Distrito Federal.

DISTRITO FEDERAL. Secretaria de Estado de Educação. Lei de Acesso a Informação. Dispõe sobre o quantitativo de Técnicos de Gestão Educacional. Processo n. SEI 00080-00183523/2019-11.

DISTRITO FEDERAL. Secretaria de Estado de Educação do Distrito Federal. Manual da Secretaria Escolar do Sistema de Ensino do Distrito Federal. Brasília: Secretaria de Estado de Educação, 2018.

DISTRITO FEDERAL. Secretaria de Estado de Educação. Portaria 23, de 24 de janeiro de 2003. Dispõe sobre a autorização para o desempenho de Secretário Escolar.

DISTRITO FEDERAL. Secretaria de Estado de Educação. Portaria 77, de 13 de abril de 2010. Dispõe sobre a autorização para o desempenho de Secretário Escolar.

DISTRITO FEDERAL. Secretaria de Estado de Educação. Portaria 92, de 17 de maio de 2010. Dispõe sobre a autorização para o desempenho de Secretário Escolar.

DISTRITO FEDERAL. Secretaria de Estado de Educação. Portaria 82, de 10 de maio de 2012. Dispõe sobre Grupo de Trabalho com a finalidade de definir as funções e atribuições das especialidades que integram os cargos da Carreira Assistência à Educação.

DISTRITO FEDERAL. Secretaria de Estado de Educação. Portaria Conjunta 28, de 16 de setembro de 2016. Dispõe sobre as especialidades e respectivas atribuições do cargo Técnico de Gestão Educacional da Carreira Assistência à Educação.

DISTRITO FEDERAL. Secretaria de Estado de Educação. Portaria 369, de 08 de novembro de 2018. Dispõe sobre a modulação de servidores das especialidades dos cargos de Agente de Gestão Educacional e Técnico de Gestão Educacional e do cargo de Monitor de Gestão Educacional da Carreira Assistência à Educação nas unidades escolares da Rede Pública de Ensino do Distrito Federal.

DISTRITO FEDERAL. Secretaria de Estado de Educação. Portaria 28, de 16 de setembro 2016. Definem as especialidades do cargo de Técnico de Gestão Educacional, Especialidade Secretário Escolar.

DISTRITO FEDERAL. Secretaria de Estado de Educação do Distrito Federal. Regimento Interno das Escolas Públicas do Distrito Federal. Brasília: 2019.

FOUCAULT, Michel. Em defesa da sociedade. Tradução Maria Ermantina de Almeida Prado Galvão. 2 ed. São Paulo: Editora Martins Fontes, 2010. 
Microfísica do Poder. Tradução de Roberto Machado. $23^{\mathrm{a}}$. ed. Rio de Janeiro:

Edições Graal, 2007.

GIANINI, Viviana Cristina; GERARDIN JÚNIOR, Ubirajara. Gestão Educacional: a atuação do profissional secretário nas organizações educacionais. Revista de Gestão e Secretariado, [S.1.], v. 1, n. 2, p. 30-50, abr. 2011. ISSN 2178-9010.

HEPP, Miriam Raquel; MARTINS, Silvana Neumann. A Secretária Executiva como facilitadora da comunicação interna em uma empresa do Vale do Taquari/rs. Revista Destaques Acadêmicos, ano 1, n. 2, 2009 - CCHJ/Univates. Disponível em: http:/ / www.univates.br/revistas/index.php/destaques/article/viewFile/17/15. Acesso em 20 abril 2020.

Instituto Nacional de Estudos e Pesquisas Educacionais Anísio Teixeira. A educação no Brasil na década de 90: 1991-2000. Instituto Nacional de Estudos e Pesquisas Educacionais Anísio Teixeira. - Brasília: Inep/MEC, 2003.

KONRAD, Fernanda Beatriz; BORGHETTI, Ana Fausta. A Secretária Executiva, o marketing pessoal e os advogados dos escritórios de Advocacia de Venâncio Aires/ RS. Revista Destaques Acadêmicos, ano 2, n. 2, 2010, CCHJ/Univates.

LOPES, Natalina Francisca Mezzari. A função do Diretor do Ensino Fundamental e Médio: uma visão história e atual. Dissertação (Dissertação em Educação). Faculdade de Educação, Universidade Estadual de Campinas, Campinas, 2003.

MONLEVADE, João Antonio Cabral de. História e Construção da Identidade Compromissos e Expectativas. Revista Retratos da Escola, Volume 3, n. 9, 2009.

NASCIMENTO, Francisco das Chagas Firmino. A Constituição dos Funcionários da Educação: formas de organização e identidade. In: GRACINDO, Regina Vinhaes; MENDONÇA, Erasto Fortes (Org.). Políticas Públicas e Gestão da Educação Básica: o Distrito Federal em foco. Brasília: Liber Livro Editora, 2010, pp. 97-118.

Os Funcionários da Educação: da construção da identidade à ação como cogestores da escola. Dissertação (Dissertação em Educação). Faculdade de Educação, Universidade de Brasília, Brasília, 2006.

SILVA, Edil Ferreira da. Trabalhadores/as de escola e construção de uma "comunidade de pesquisa": a busca da promoção da saúde a partir da dos locais de trabalho. Tese (Doutorado em Saúde). Fundação Osvaldo Cruz, Escola Nacional de Saúde Pública, Rio de Janeiro, 2003.

TRIBUNAL DE CONTAS DO DISTRITO FEDERAL. Processo 14822, de 25 de maio de 2016. Inspeção na Secretaria de Estado de Educação. 